\title{
Prediction of Nonlinear Cyclic Behaviors of Shear Wall Composed of Acacia mangium Framing and Fiber Cement Board Sheathing
}

\author{
Maryoko Hadi, Satoru Murakami, Kohei Komatsu \\ Laboratory of Structural Function, Kyoto University, Kyoto, Japan \\ Email: maryokohadi@gmail.com
}

Received December 10, 2011; revised January 15, 2012; accepted January 22, 2012

\begin{abstract}
The alternative types of composite structure made of wood and cement based building materials needs to meet with the high demand for earthquake-resistant houses in Indonesia. In order to understand the mechanism of earthquake resisting performance of shear wall, it is necessary to investigate not only elastic behavior of shear walls but also non-linear one. In this study, series of full-scale experiments on timber frame shear walls composed of Akasia wood (Acacia mangium) sheathed by Fiber Cement Board (FCB) were carried out. For predicting skeleton curve, a series of theoretical equations was derived, which cannot only solve arbitrary nail pattern shear wall but also nonlinear behavior after yielding. Further, for describing hysteresis loops of shear walls, so-called Normalized Cyclic Loop (NCL) model was adopted. By combining two theoretical approaches, weintended to predict whole cyclic shear wall behaviors tested. Good agreements were obtained from comparison between experiment and prediction. The information obtain by this study will be useful for practical engineers or structural designers to design the high performance earthquake resisting timber houses.
\end{abstract}

Keywords: Earthquake-Resistant House; Shear Wall; Akasia Wood; FCB

\section{Introduction}

From recent damage due to earthquakes in various places in Indonesia, it appears that residential houses made of concrete and/or masonry was insufficient and collapsed in severe earthquakes. More than fifteen years ago in Kobe, Japan, there was also a severe earthquake and devastating damage was observed on many timber houses. Since then, not only the Japanese government but also universities, institutes and commercial companies have been paying effort to make timber residential houses stiffer, stronger and tougher. Following this good previous example, an attempt was initiated in Indonesia to make residential houses more capable of surviving severe earthquakes in the future.

This paper aimed for establishing reliable shear walls by using Akasia wood frame, sheathed with Fiber Cement Board (FCB), which is similar to those being used for earthquake-resisting house in Indonesia.

In order to understand the mechanism of earthquake resisting performance of shear wall, we need to investigate non-linear behaviors of shear walls. For this end, the new theoretical equations derived, which can not only solve arbitrary nail pattern shear wall but also nonlinear behavior after yielding for obtaining skeleton curve. In addition to this, the Normalized Cyclic Loop (NCL) mo- dels for predicting hysteresis loops were used. And by combining these two theoretical approaches, intended to predict whole non-linear cyclic behaviors of shear walls, which were composed of Akasia wood frame and nail on FCB sheathing.

\section{Material and Methods}

\subsection{Framing Materials}

The Indonesian Akasia wood (Acacia mangium) of $40 \times$ $80 \times 3000 \mathrm{~mm}$ solid timber was used for all of framing member material shown in Figure 1, whose mechanical and physical properties are shown in Table 1.

The Spruce glulam beam of $120 \times 120 \mathrm{~mm}$ cross-section was used for loading girder.

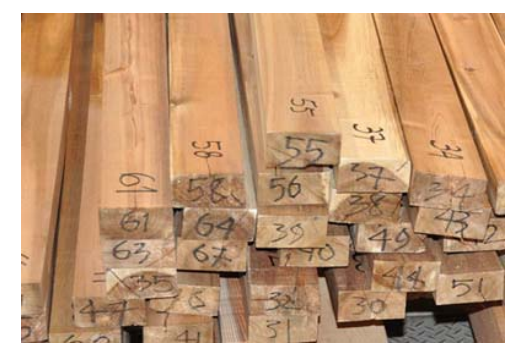

Figure 1. Akasia wood used as shear wall frames member. 
Table 1. Akasia's wood mechanical and physical of material property.

\begin{tabular}{cccc}
\hline Property & Number of Sample & Value (CV) & Unit \\
\hline Density & 41 & $529.3(16.0)$ & $\left(\mathrm{kg} / \mathrm{m}^{3}\right)$ \\
$\begin{array}{c}\text { Dynamic Modulus of } \\
\text { Elasticity; MOE }\end{array}$ & 41 & $10.32(12.8)$ & $\left(\mathrm{kN} / \mathrm{mm}^{2}\right)$ \\
\hline
\end{tabular}

\subsection{Sheathing Materials}

The Sheathing material is Fiber Cement Board (FCB), in which Silica (35\% by weight), calcium (35\% by weight), pulp and wooden fiber (15\% by weight) and others (15\% by weight) produced by the Japanese commercial company with size of $1800 \times 900 \times 12 \mathrm{~mm}$ shown in Figure 2. The material properties of FCB are given in Table 2.

\subsection{Fasteners}

Two kinds of nails were used and their specification is shown in Table 3.

The N100 nails, which were used for fastener connection between frame member and the N75 used as fastener of FCB that were attached to the frame member shown in Figure 3.

\subsection{Shear Wall Specimen}

Two types of specimen were prepared as shown in Figures 4 and 5. Test specimens named, as SWC is conventional type shear wall, which has been used in Indonesia currently; while test specimen named as SWB is an alternative shear wall type, which was proposed in previous study [1]. Nailing pitch in both type of shear walls were $150 \mathrm{~mm}$.

\subsection{Testing Methods of Single Shear between Sheathing and Frame Member}

The single shear test between Akasia wood and FCB sheathing material was carried out, to obtain non-linear load slip curve, which dominates non-linear behavior of shear wall. Akasia specimen size; $40 \times 80 \times 150 \mathrm{~mm}, 12$ mm thick of FCB and fastened by N75 nail, shown in Figures 6 and 7. Test speed was $1 \mathrm{~mm}$ per minute on Universal Testing Machine (UTM).

\subsection{Cyclic Testing Methods}

Figure 8 shows testing set-up and location of measuring devices. Loading protocol used in this study was tentatively determined in accordance with usual shear wall testing method in Laboratory of Structural Function, Kyoto University. Therefore, only one cyclic loading in each target deformation angle loop were used, as shown in below.

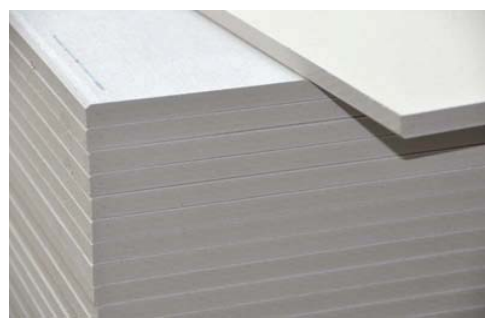

Figure 2. FCB used as frame specimen sheathed.

Table 2. Mechanical and physical properties of FCB.

\begin{tabular}{ccc}
\hline Property & Value & Unit \\
\hline Density & 1220 & $\left(\mathrm{~kg} / \mathrm{m}^{3}\right)$ \\
Modulus of Elasticity; MOE ${ }^{1}$ & 31.67 & $\left(\mathrm{kN} / \mathrm{mm}^{2}\right)$ \\
Shear Modulus; $\mathrm{G}^{1}$ & 700 & $\left(\mathrm{~N} / \mathrm{mm}^{2}\right)$ \\
\hline${ }^{1}$ Catalog of Company's Product (not published). &
\end{tabular}

Table 3. Nail specification.

\begin{tabular}{cccl}
\hline Name & Diameter $(\mathrm{mm})$ & Length $(\mathrm{mm})$ & \multicolumn{1}{c}{ Remarks } \\
\hline N75 & 2.85 & 75 & $\begin{array}{l}\text { Between sheathing and } \\
\text { frame member } \\
\text { N100 }\end{array}$ \\
\hline
\end{tabular}

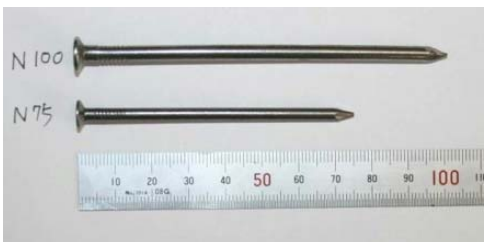

Figure 3. The steel nail used as fastener for all connection.

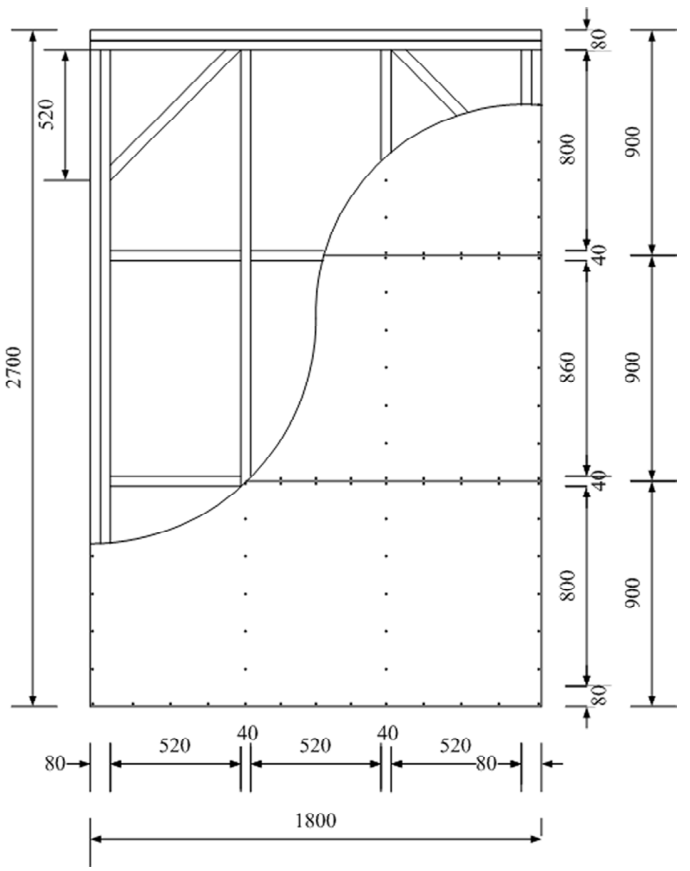

Figure 4. SWC: the $C$ (Conventional) shear wall frame and nailing pattern. 


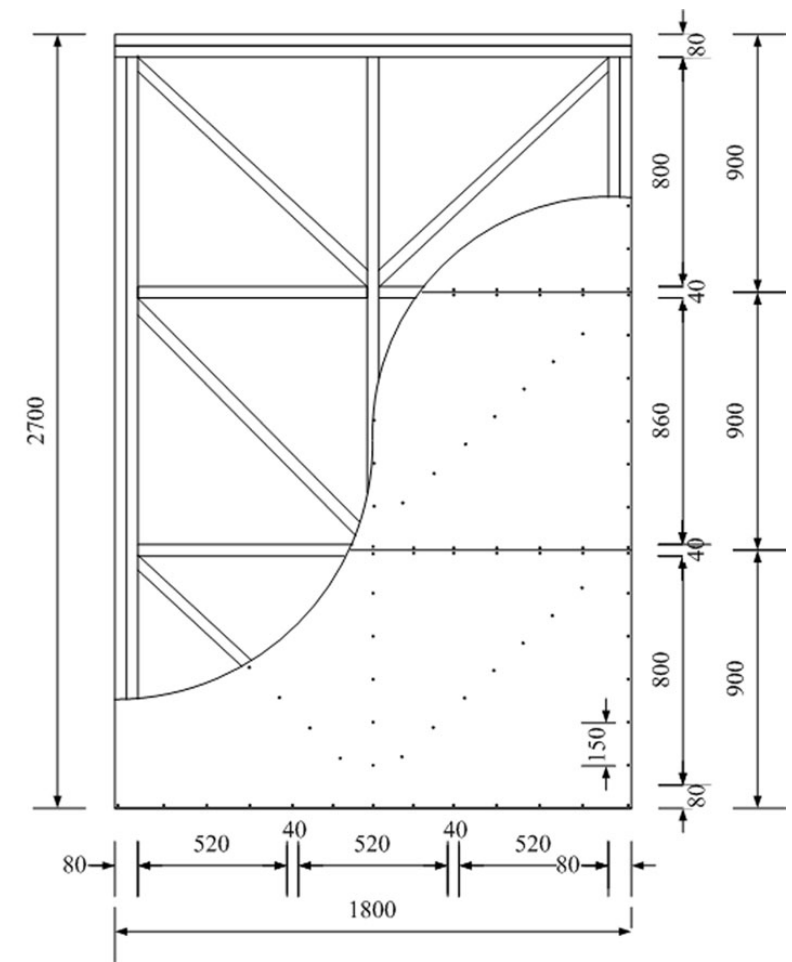

Figure 5. SWB: the V brace shear wall frame and nailing pattern.

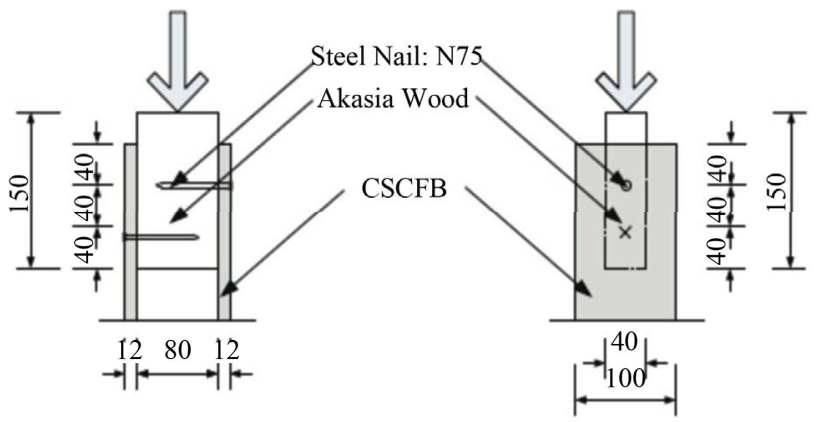

Figure 6. Shear test specimen of Akasia wood and FCB fastened by N75 nail.

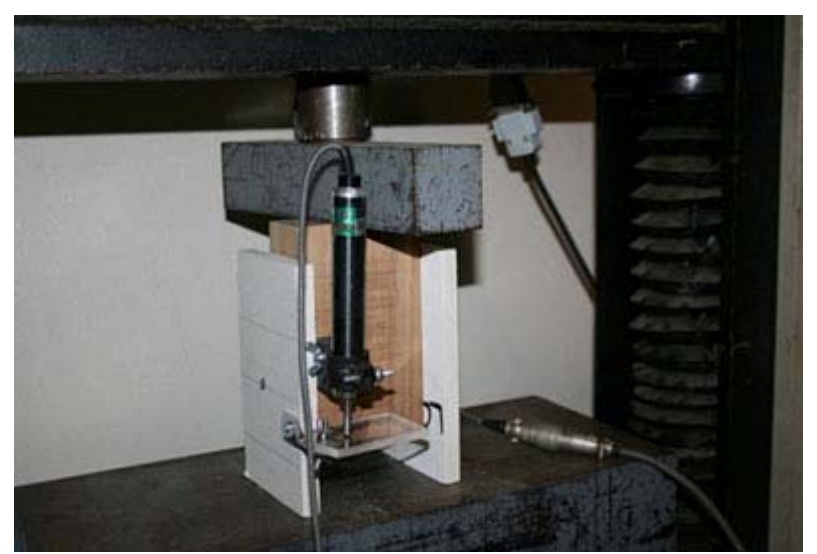

Figure 7. Shear test specimen of Akasia wood and FCB fastened by N75 nail during test.

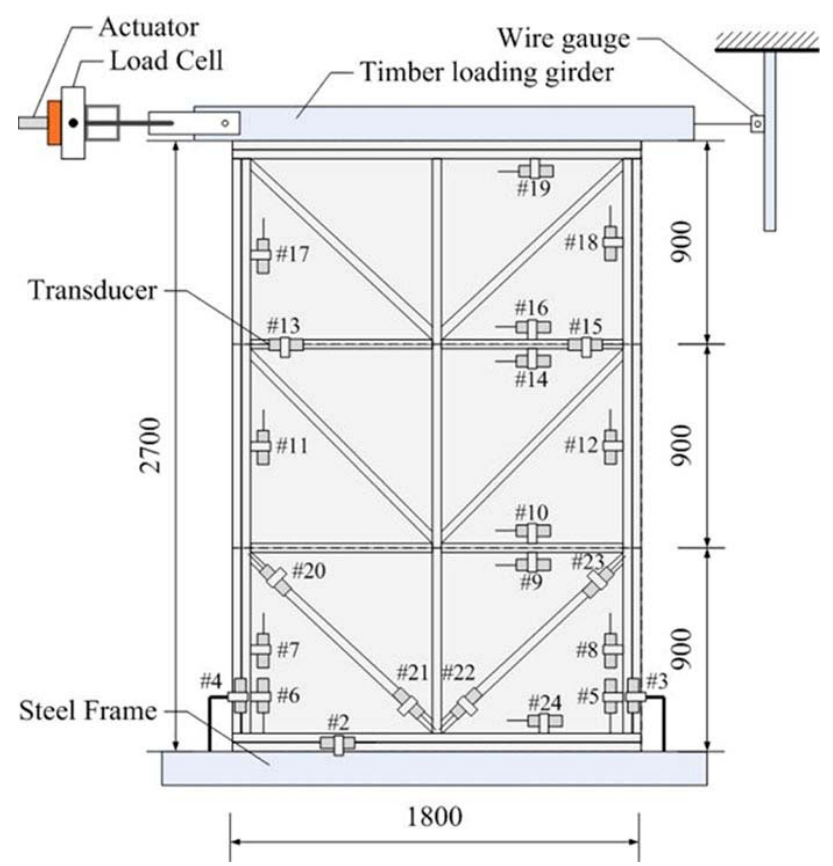

Figure 8. Testing set-up of shear wall specimen.

First loop: $0 \leftrightarrow 1 / 300 \mathrm{rad}$

Second loop: $0 \leftrightarrow 1 / 200 \mathrm{rad}$

Third loop: $0 \leftrightarrow 1 / 150$ rad

Fourth loop: $0 \leftrightarrow 1 / 100 \mathrm{rad}$

Fifth loop: $0 \leftrightarrow 1 / 75 \mathrm{rad}$

Sixth loop: $0 \leftrightarrow 1 / 60 \mathrm{rad}$

Seventh loop: $0 \leftrightarrow 1 / 30 \mathrm{rad}$

Eighth loop: $0 \leftrightarrow 1 / 15$ rad

Final loading: $0 \rightarrow p_{\max } \rightarrow-p_{\max } \rightarrow 0$

The horizontal push and pull of static cyclic load as represent of earthquake loading was applied using the hydraulic actuator of $500 \mathrm{kN}$ capacity and $500 \mathrm{~mm}$ strokes.

The top of shear wall specimen displacement was measured by using displacement-measuring device of 500 $\mathrm{mm}$ strokes. Small displacement and rotation of shear wall were measured by using displacement meter of $50 \mathrm{~mm}$ strokes. Figures $\mathbf{9}$ and $\mathbf{1 0}$ show the $\mathrm{V}$ and $\mathrm{C}$ brace and the shear wall specimen during testing.

\section{Theory and Calculation}

\subsection{Analytical Methods for Predicting Envelop Curve}

The following nonlinear calculation method was derived based on the article written by Murakami and Inayama [2] but modified so as to be applicable to such nailed-onsheathed shear walls whose nailing pattern are arbitrary arranged. 


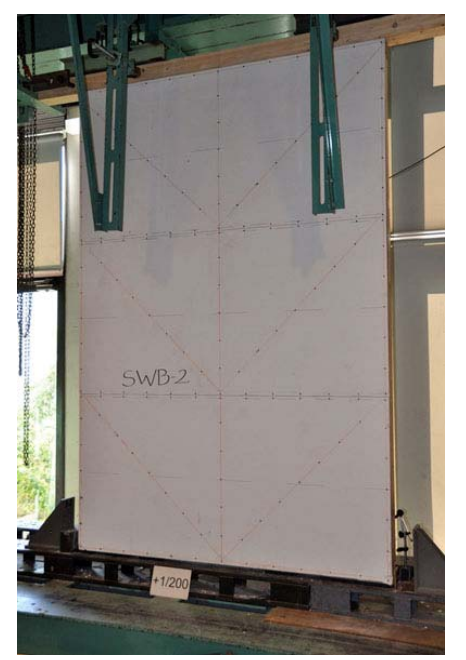

Figure 9. The V brace frame CFB sheathed during test.

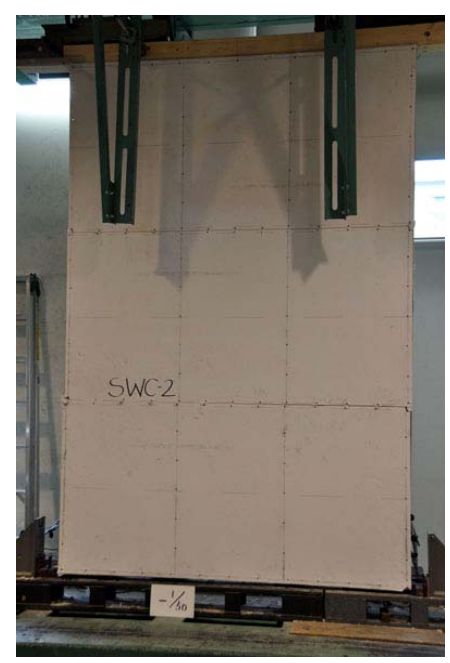

Figure 10. The $\mathrm{C}$ brace with $\mathrm{CFB}$ sheathed during test.

\subsubsection{Derivation of Equations \\ 1) Definition of Nail Position}

Figure 11 shows nail positions and rotational center defined in the Cartesian coordinate system where the origin was determined arbitrary to be located at bottom left corner and a total of $n$ nails are located arbitrary starting from I $=1$ to $n^{\text {th }}$ in a rectangular area of $g \times L$ as shown in Figure 11.

Let us assume that slip modulus of nail $K_{s}$ is not orthotropic but having different values in each nail as this assumption will make it possible to execute step by step nonlinear calculation with considering material nonlinearity of each nail and movement of rotation center from the initial position to any ones which is ought to be determined by equilibrium of nail forces.

\section{2) Derivation of Rotation Center}

At first, let us assume a situation that a forced rotational deformation of angle $\theta_{x}$ was given around the rotation center as shown in Figure 12. Due to this forced

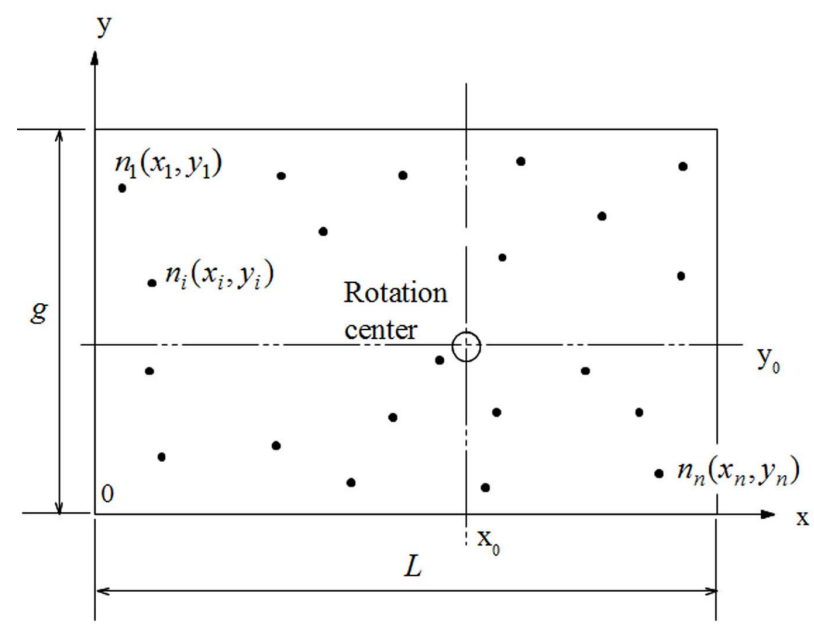

Figure 11. Definition of nail position and rotation center in the Cartesian coordinate system.

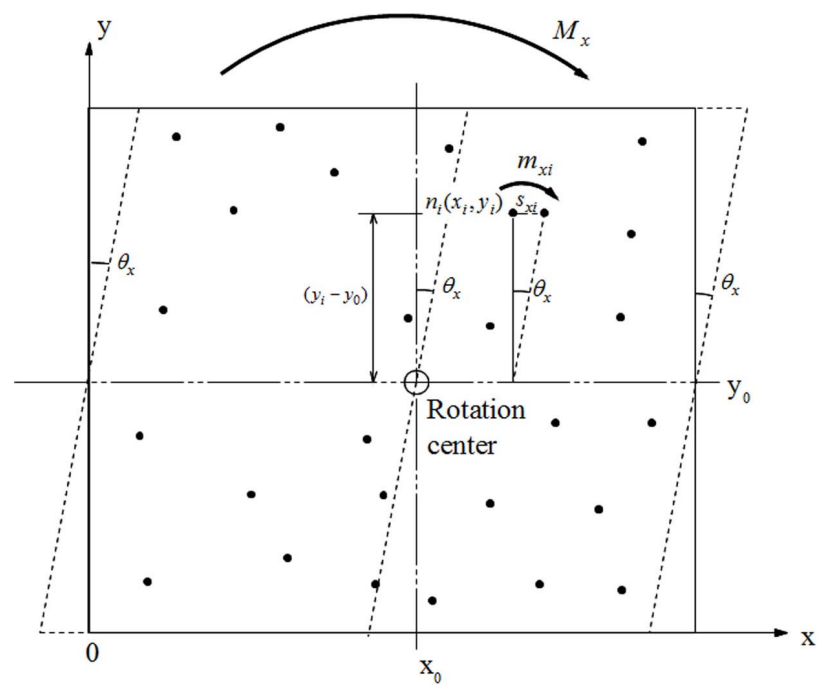

Figure 12. Displacement of $\boldsymbol{i}^{\text {th }}$ nail due to forced rotational deformation $\theta_{x}$.

deformation, $i^{\text {th }}$ nail $n_{i}$ will be displaced to $x$-direction by the amount of $s_{x i}$ as shown in Equation (1).

$$
s_{x i}=\left(y_{i}-y_{0}\right) \theta_{x}
$$

Denoting slip modulus of $i^{\text {th }}$ nail as $K_{s i}$, the reaction force acting on $i^{\text {th }}$ nail can be expressed as Equation (2).

$$
p_{x i}=s_{x i} \times K_{s i}=K_{s i}\left(y_{i}-y_{0}\right) \theta_{x}
$$

Equilibrium of all $p_{x i}$ along $x$-direction leads to Equation (3).

$$
\sum p_{x i}=0 \rightarrow \sum K_{s i}\left(y_{i}-y_{0}\right) \theta_{x}=0
$$

As $\theta_{x}$ is constant, then Equation (3) leads to Equation (4).

$$
\sum K_{s i}\left(y_{i}-y_{0}\right)=0 \rightarrow \sum K_{s i} y_{i}=\sum K_{s i} y_{0} \rightarrow y_{0}=\frac{\sum K_{s i} y_{i}}{\sum K_{s i}}
$$


From the same derivation process as shown in $x$-directional case, by assuming forced rotational deformation with angle $\theta_{y}$ as shown in Figure 13, $x$-directional rotation center can be derived as shown in Equation (5).

$$
x_{0}=\frac{\sum K_{s i} x_{i}}{\sum K_{s i}}
$$

\section{3) Derivation of Shear Deformation of Partial Shear Wall}

Again let us consider x-directional displacement $s_{x i}$ of $i^{\text {th }}$ nail due to $\theta_{x}$;

$$
s_{x i}=\left(y_{i}-y_{0}\right) \theta_{x}
$$

Reaction force acting on the $i^{\text {th }}$ nail is;

$$
p_{x i}=s_{x i} \times K_{s i}=K_{s i}\left(y_{i}-y_{0}\right) \theta_{x}
$$

Individual small rotational moment due to reaction force $p_{x i}$ is;

$$
m_{x i}=p_{x i} \times\left(y_{i}-y_{0}\right)=K_{s i}\left(y_{i}-y_{0}\right)^{2} \theta_{x}
$$

X-directional total moment $M_{x}$ is;

$$
M_{x}=\sum_{i=1}^{n} m_{x i}=\sum_{i=1}^{n} K_{s i}\left(y_{i}-y_{0}\right)^{2} \theta_{x}=\theta_{x} \sum_{i=1}^{n} K_{s i}\left(y_{i}-y_{0}\right)^{2}
$$

In the same way, $y$-directional total moment $M_{y}$ can be obtained as Equation (10).

$$
M_{y}=\sum_{i=1}^{n} m_{y i}=\sum_{i=1}^{n} K_{s i}\left(x_{i}-x_{0}\right)^{2} \theta_{y}=\theta_{y} \sum_{i=1}^{n} K_{s i}\left(x_{i}-x_{0}\right)^{2}
$$

As $M_{x}$ and $M_{y}$ must be equilibrium, then Equation (11) should be held good.

$$
\begin{gathered}
M_{x}=M_{y} \\
\theta_{x} \sum_{i=1}^{n} K_{s i}\left(y_{i}-y_{0}\right)^{2}=\theta_{y} \sum_{i=1}^{n} K_{s i}\left(x_{i}-x_{0}\right)^{2} \rightarrow \frac{\theta_{x}}{\theta_{y}} \\
=\frac{\sum_{i=1}^{n} K_{s i}\left(x_{i}-x_{0}\right)^{2}}{\sum_{i=1}^{n} K_{s i}\left(y_{i}-y_{0}\right)^{2}}=\frac{I_{x}}{I_{y}}
\end{gathered}
$$

While, in Figure 14 shown thatpartial external shear force $Q$ applied on the top of the corresponding shear wall of height " $g$ " gives a rotational moment $Q \cdot g$ and this moment should be equilibrated with each internal moment $M_{x}$ and $M_{y}$.

$$
\begin{aligned}
& Q g=M_{x}=M_{y} \\
& \rightarrow Q g=\theta_{x} \sum K_{s i}\left(y_{i}-y_{0}\right)^{2}=\theta_{y} \sum K_{s i}\left(x_{i}-x_{0}\right)^{2} \\
& \rightarrow \theta_{x}=\frac{Q g}{\sum K_{s i}\left(y_{i}-y_{0}\right)^{2}} \\
& \rightarrow \theta_{y}=\frac{Q g}{\sum K_{s i}\left(x_{i}-x_{0}\right)^{2}}
\end{aligned}
$$

The shear deformation angle $\gamma_{n}$ of the shear wall caused

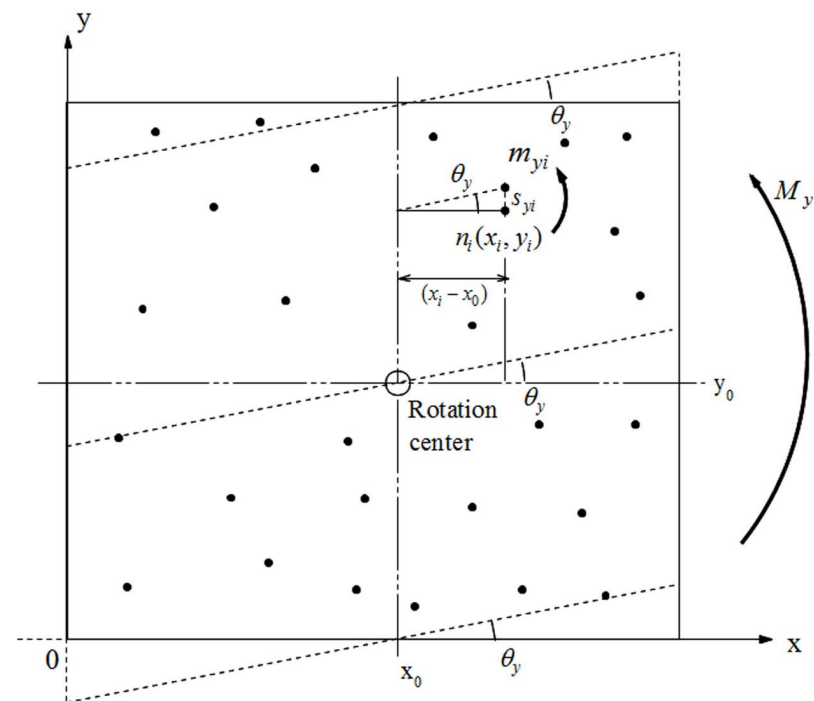

Figure 13. Displacement of $\boldsymbol{i}^{\text {th }}$ nail due to forced rotational deformation $\theta_{y}$.
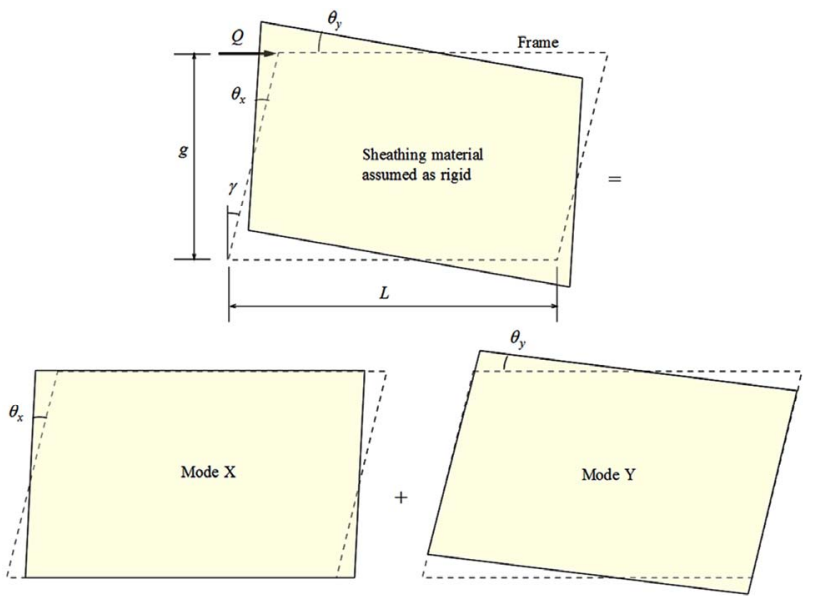

Figure 14. Assumed deformation mode in partial shear wall of $g \times L$ size.

by nail slip will be defined as the summation of $x$-directional rotation $\theta_{x}$ and y-directional rotation $\theta_{y}$ just same as the definition of shear strain of solid materials, thus,

$$
\gamma_{n}=\theta_{x}+\theta_{y}
$$

Substituting Equation (13) into (14), we can get the final relationship between applied shear forces $Q$ and shear deformation angle $\gamma_{n}$ as in Equation (15).

$$
Q=\frac{1}{g} \times \frac{\sum K_{s i}\left(y_{i}-y_{0}\right)^{2} \times \sum K_{s i}\left(x_{i}-x_{0}\right)^{2}}{\sum K_{s i}\left(y_{i}-y_{0}\right)^{2}+\sum K_{s i}\left(x_{i}-x_{0}\right)^{2}} \gamma_{n}=K_{n} \cdot \gamma_{n}
$$

where,

$$
K_{n}=\frac{1}{g} \times \frac{\sum K_{s i}\left(y_{i}-y_{0}\right)^{2} \times \sum K_{s i}\left(x_{i}-x_{0}\right)^{2}}{\sum K_{s i}\left(y_{i}-y_{0}\right)^{2}+\sum K_{s i}\left(x_{i}-x_{0}\right)^{2}}
$$

$K_{n}=$ Shear rigidity component due to nail resistance. 
If the shear deformation due to sheathing material itself should be taken into account, the relationship between shear force $Q$ and shear deformation angle $\gamma_{n}$ will be expressed as Equation (16).

$$
Q=G L t \cdot \gamma_{S}
$$

where, $G$ is shear rigidity of sheathing materials.

$L$ is length of shear wall.

$t$ is thickness of sheathing materials.

Hence, the total shear deformation angle $\gamma$ of shear wall will be written as the summation of shear deformation angle as;

$$
\gamma=\gamma_{n}+\gamma_{S}=\left\{\frac{1}{K_{n}}+\frac{1}{G L t}\right\} Q=\frac{1}{K_{P S W}} Q
$$

where, $\frac{1}{K_{P S W}}=\left\{\frac{1}{K_{n}}+\frac{1}{G L t}\right\}$

is total shear stiffness of partial shear wall.

\section{4) Derivation of Shear Deformation of Whole Shear} Wall

In general, whole shear wall tends to be composed of plural partial shear walls due to unit size of sheathing material as shown in Figure 15.

From equilibrium condition of external and internal moment, Equation (18) should be held good.

$$
P H=\sum Q_{j} g_{j}
$$

The compatibility condition that all partial shear walls should share the same deformation angle will lead to Equation (19),

$$
\gamma_{W S W}=\gamma_{j}
$$

where, the suffix “ $j$ ” indicates number of partial shear wall. Substituting Equation (17) into (18) and considering (19), finally we can get Equation (20) for the loadshear deformation relationship of whole shear wall.

$$
P=\left(\frac{\sum K_{P S W-j} \cdot g_{j}}{H}\right) \cdot \gamma_{W S W}
$$

\subsubsection{Nonlinear Calculation Method}

\section{1) Load-Slip Data of Nail for Non-Linear Calculation Method}

Figure 16 shows load-slip data of N75 nail taken from single shear test on Akasia wood with FCB sheathing. For this data, a three-parameters exp-equation shown in Equation (21) was fitted up to maximum load for nonlinear calculation. And beyond maximum load level, simple linear equation showed on (22),

$$
p=\left(p_{u}+K_{u} \cdot s\right)\left\{1-\exp \left(\frac{-K_{s}}{p_{u}} s\right)\right\}
$$

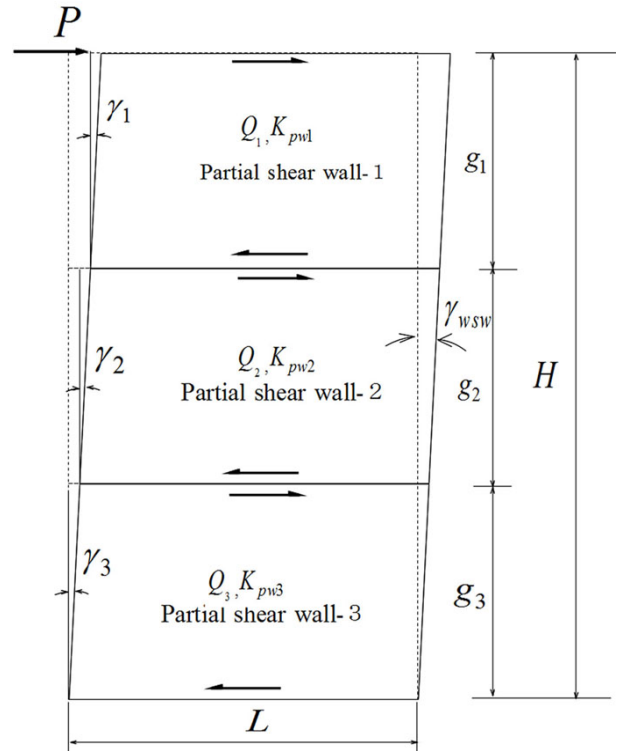

Figure 15. Relationship between whole shear wall and partial shear walls.

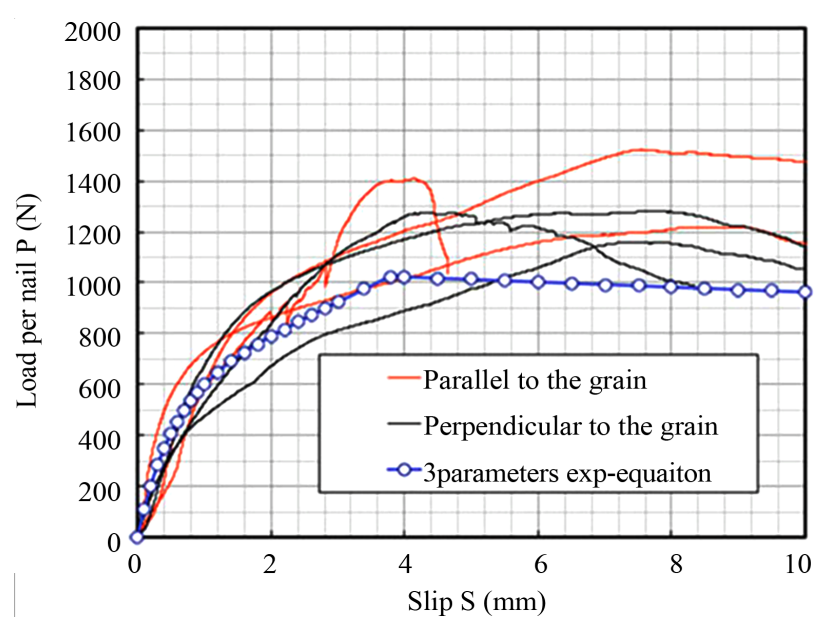

Figure 16. The single nail shear test result.

$$
p=p_{\max }-K_{u 2} \cdot\left(s_{p \max }-s\right)
$$

where, $p_{\mathrm{u}}=550 \mathrm{~N}, K_{u}=-10 \mathrm{~N} / \mathrm{mm}, K_{s}=1200 \mathrm{~N} / \mathrm{mm}$, $K_{u 2}=-10 \mathrm{~N} / \mathrm{mm}$.

\section{2) Non-Linear Calculation Procedure}

Figure 17 shows flow chart of non-linear calculation procedure in this study.

\subsection{Modeling of Hysteresis Loop}

In order to analyze dynamic property of shear walls it is necessary to established any appropriate hysteresis loop model. In this study we adopted so-called Normalized Characteristic Loop (NCL) Model that was proposed by Tani and Nomura $[3,4]$ for reinforced concrete structures and recently modified by Matsunaga, Miyazu and Soda [5-7] for timber shear structures. 


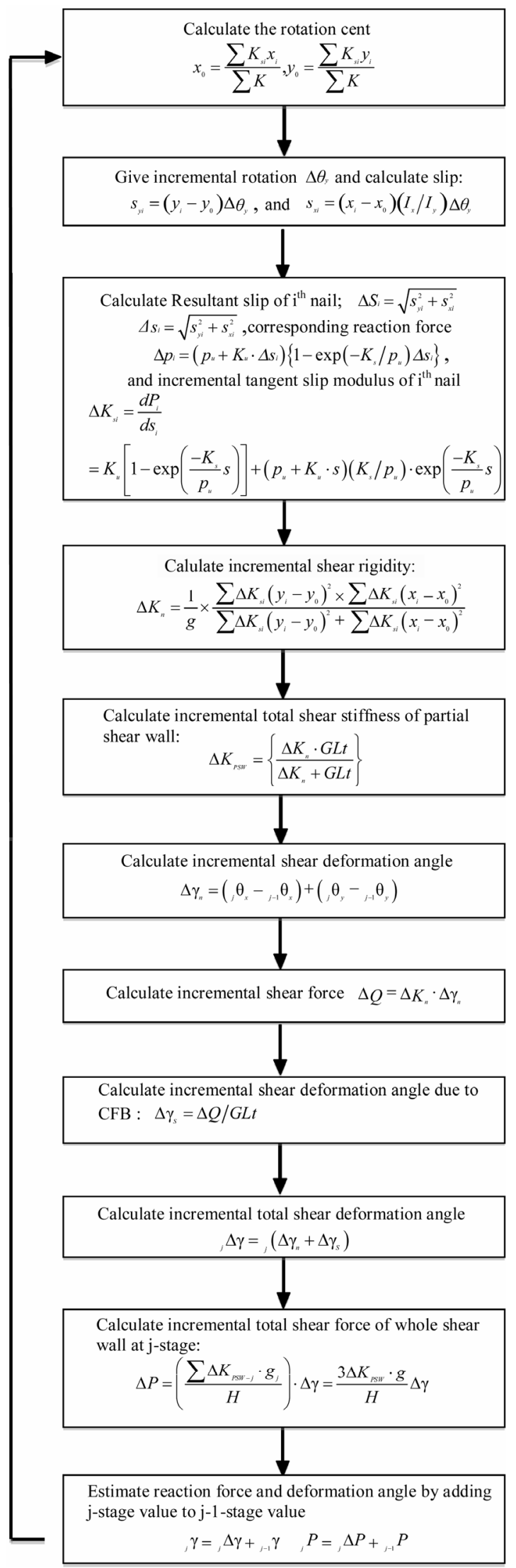

Figure 17. Flow chart of non-linear calculation procedure.
Figures 18 and 19 show the NCL Model for Akasia frame and FCB sheathing shear wall system were expressed by following Equation (23) in accordance with the studies of Matsunaga, Miyazu and Soda [5-7],

$$
\begin{aligned}
& \text { Loading : } L(x)=\left(B \cdot|x|^{n 1}+1-B\right) x \mp A\left(x^{4}-1\right) \\
& \text { Un-Loading : } L(x)=\left(B \cdot|x|^{n 2}+1-B\right) x \mp A\left(x^{4}-1\right)
\end{aligned}
$$

where, $L(x)$ and $x$ are normalized load and deformation angle respectively divided by maximum value in each loop and $A, B, n 1$ and $n 2$ are parameters governing shape of hysteretic loop. In the second term of Equation (23), the minus mark should be used in the case of upper curve while plus mark should be used in the case of lower curve. Four parameters are shown in Table 4.

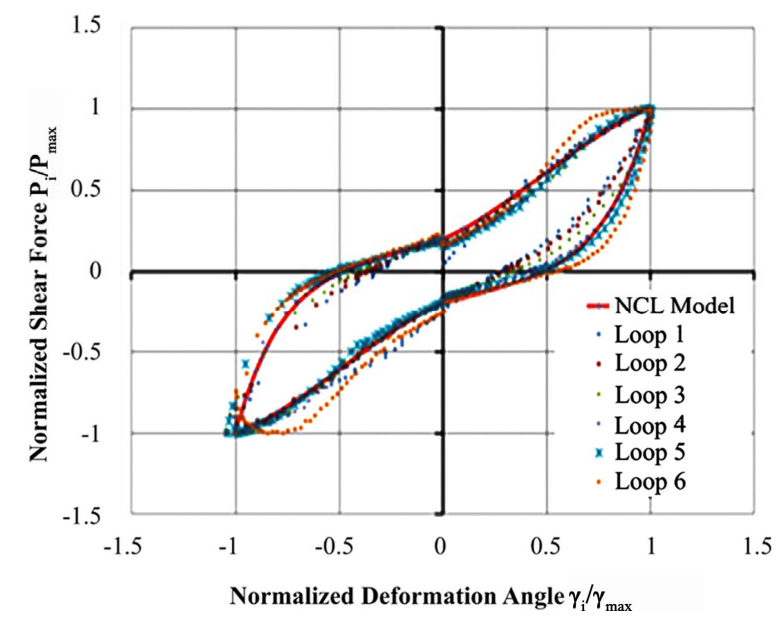

Figure 18. NCL model for conventional type shear wall (SWC).

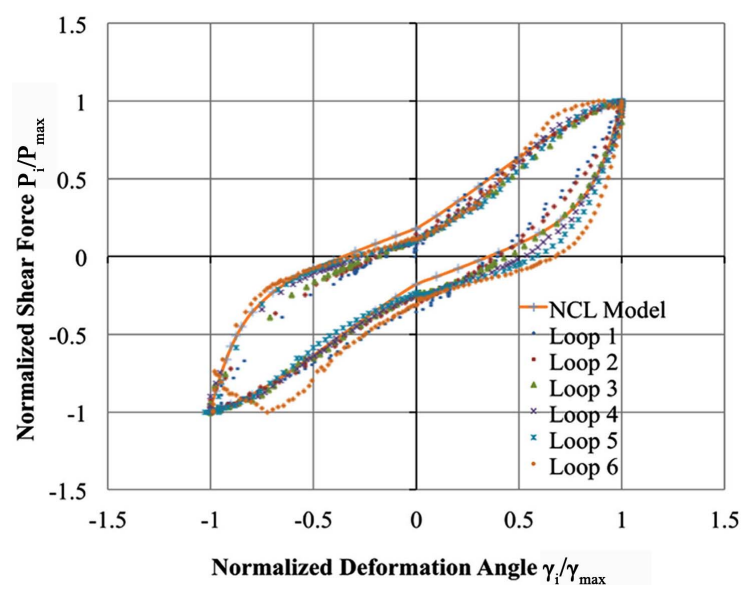

Figure 19. NCL model for V-brace type shear wall (SWB).

Table 4. Four parameter of NCL model for shear wall.

\begin{tabular}{ccccc}
\hline & B & A & $n 1$ & $n 2$ \\
\hline SWC & 0.63 & 0.20 & 0.4 & 4.5 \\
SWB & 0.50 & 0.18 & 0.2 & 8.0 \\
\hline
\end{tabular}




\section{Results and Discussions}

\subsection{Envelope Curve}

Figures 20 and 21 show comparisons between predicted envelope curve and experimental ones. As can be seen from SWC specimens, prediction coincident with experimental ones well, while in the case of SWB specimen, prediction over-estimated performances of shear walls after yielding a little bit. The reason why only one specimen was used for the comparison in SWB specimen is that in experimental procedure, tests were carried out for two specimens without sufficient restriction from up-lift of test specimens. Therefore, the load-deformation curves of those specimens without restriction became abnormal. The rest of one specimen was tested with sufficient restriction for up-lift thus normal load-deformation curve that was usable for the comparison between experiment and prediction was obtained. Therefore, the discrepancy for SWB specimen might be fallen down into the experimental variance.

Figure 22 shows initial failure at edge nail, which occurs at 1/75 radian deformation angle due to insufficient edge distance. This kind of initial failure could not be predicted by the theory derived in this study therefore in order to predict this kind of initial failure precisely, nail shear data having effect of insufficient edge distance should be used in the analysis. Figure 23 shown failure of FCB at $1 / 15$ radian.

\subsection{Whole Load Deformation Curve}

Figures 24 and 25 show comparisons between experimental

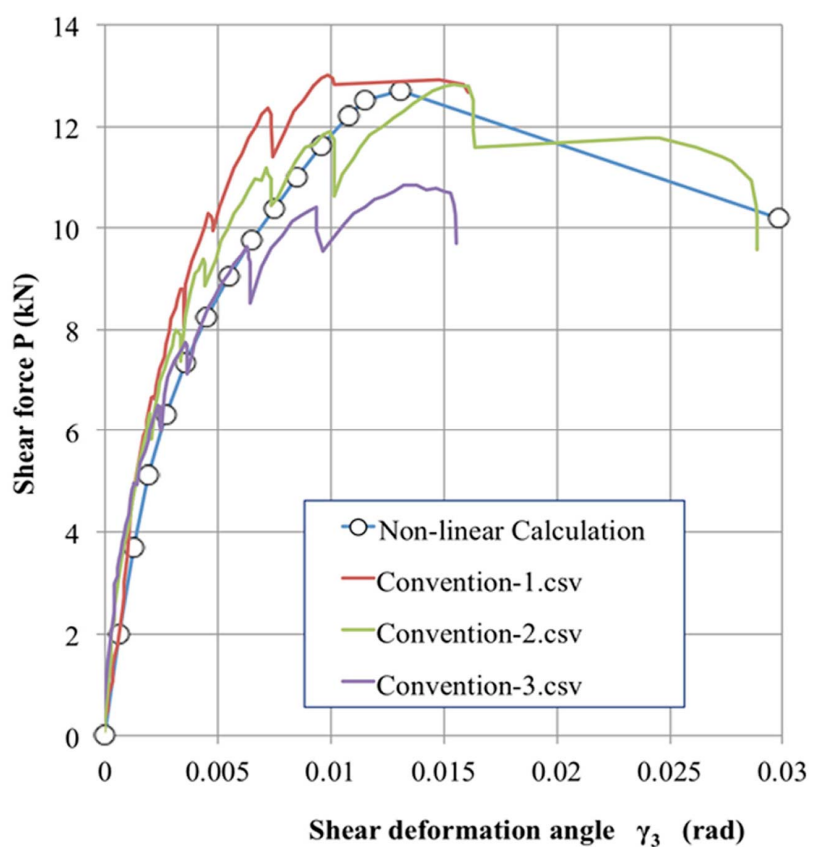

Figure 20. Comparison between predicted envelope curve and experimental result for conventional shear wall (SWC).

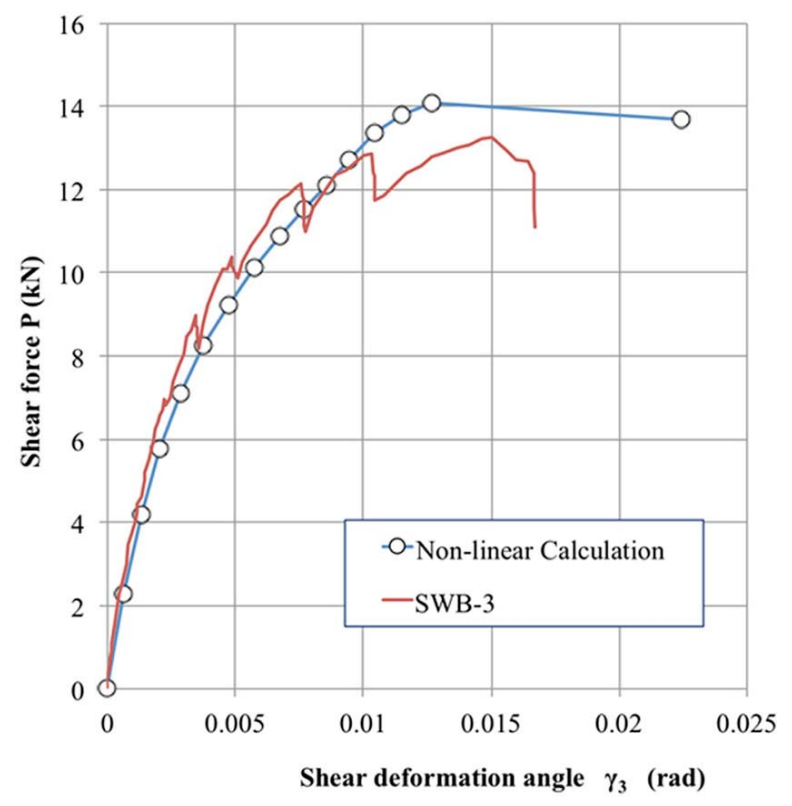

Figure 21. Comparison between predicted envelope curve and experimental result for brace type shear wall (SWB).

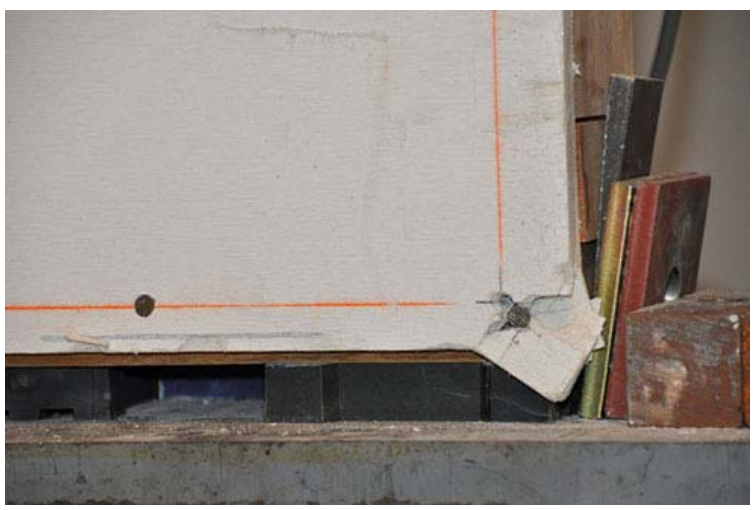

Figure 22. Initial failure at edge nail in 1/75 radian deformation level.

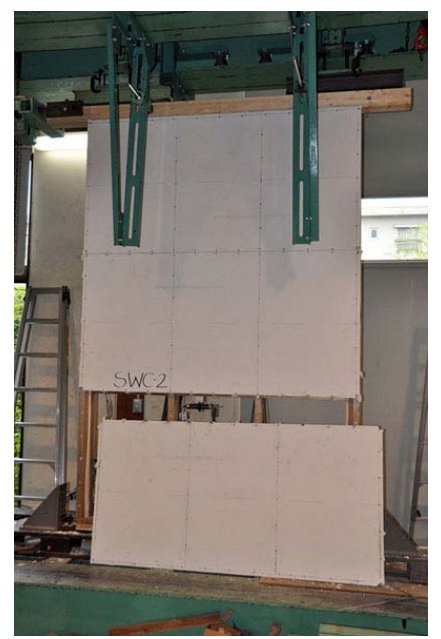

Figure 23. The specimen at final condition in 1/15 radiandeformation level. 


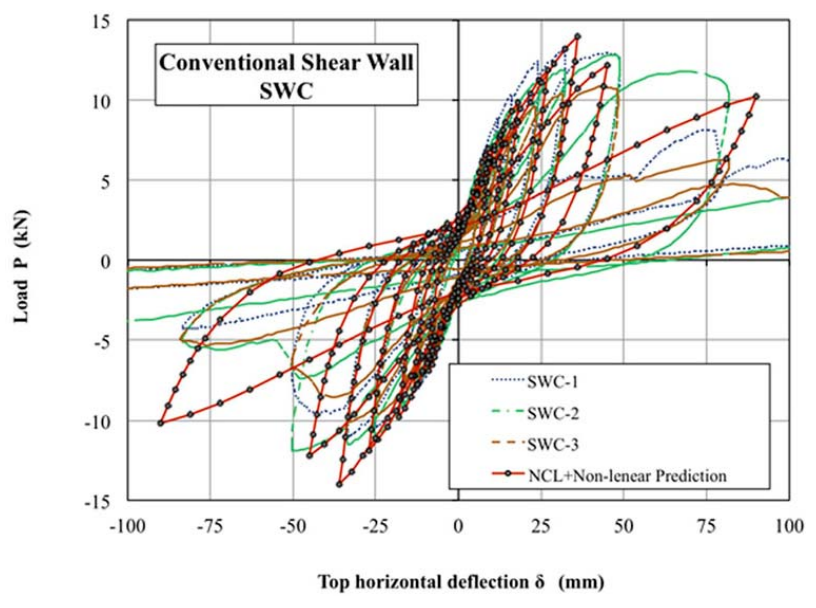

Figure 24. Comparison between predicted load deformation curve and experimental ones for SWC specimen.

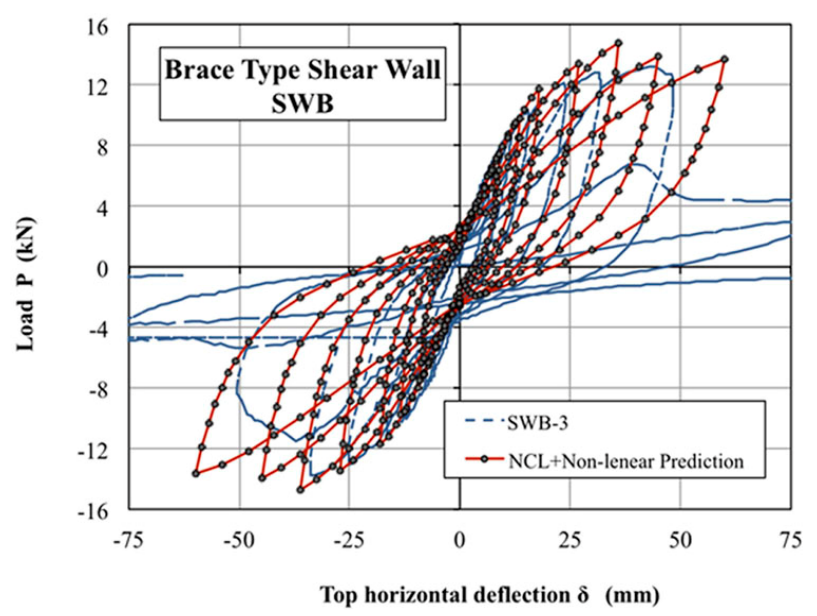

Figure 25. Comparison between predicted load deformation curve and experimental ones for SWB specimen.

curve and theoretical prediction, which was obtained by combining, envelop curve with hysteresis NCL Model.

Although there are some sorts of discrepancy between prediction and experimental results, comparisons shown in this study seemed to be fairy good at least for predicting whole nonlinear behaviors of wooden shear walls whose nailing pattern are arbitrary arranged. These comparisons might suggest that better prediction will be obtained by paying careful attention to nail shear data so as to be reflected by in sufficient edge distance effect.

\section{Conclusion}

In this study we derived a non-linear calculation method for predicting whole load-deformation curve of FCB sheathed nail-on shear wall made by Akasia wood frame.
NCL Model formulated hysteresis loops. By combining these two theoretical methods we could predict whole nonlinear cyclic load-deformation behavior of specimens. Although there were some discrepancies between prediction and experimental observations, further better prediction might be obtain by paying careful attentions to nail shear data so as to be reflected in sufficient edge distance effect.

\section{Acknowledgements}

We would like to express our sincere thanks to JSPS for Ronpaku program, Structural Function Laboratory, RISH, Kyoto University, Japan, Dr. Akihisa Kitamori, Structural Function Laboratory, RISH, Kyoto University, Japanand RIHS, Ministry of Public Works of Indonesia for all research activity.

\section{REFERENCES}

[1] M. Hadi, S. Murakami, A. Kitamori, W.-S. Chang and K. Komatsu, "Performance of Shear Wall Composed of LVL and Cement Fiber Board Sheathing,” Journal of Asian Architecture and Building Engineering, Vol. 9, No. 2, 2010, pp. 463-469. doi:10.3130/jaabe.9.463

[2] M. Murakami and M. Inayama, "Formulae to Predict the Elastic and Plastic Behaviour of Shearwall with Any Nailing Arrangement Pattern,” Journal of Structural and Construction Engineering, Transactions of AIJ, Vol. 519, 1999, pp. 87-93.

[3] S. Tani, S. Nomura, T. Nagasawa and A. Hiramatsu, "Restoring Force Characteristics of Reinforced Concrete Aseismatic Elements (Part 1): Restoring Force Characteristics and Metallization," Transactions of Architectural Institute of Japan, Vol. 202, 1972, pp. 11-19.

[4] S. Tani, S. Nomura, T. Nagasawa and A. Hiramatsu, "Restoring Force Characteristics of Reinforced Concrete Seismic Elements (Part 3): Restoring Force Characteristics on Dynamic Response of Structure," Transactions of Architectural Institute of Japan, Vol. 228, 1975, pp. 39-48.

[5] H. Matsunaga, S. Soda and Y. Miyazu, "Modeling of Restoring Force Characteristics of Wooden Structures and Its Application to Dynamic Analyses," Proceeding of the $78^{\text {th }}$ Architectural Research Meetings, 2007, Architectural Institute of Japan, Kanto Chapter, 2008, pp. 201-204.

[6] H. Matsunaga, Y. Miyazu and S. Soda, “Time History Seismic Response Analysis for Wooden Structure Applied Extended NCL Model," Summaries of Technical Papers of Annual Meeting Architectural Institute of Japan. C-1, Structures III, 2008, pp. 181-182.

[7] H. Matsunaga, Y. Miyazu and S. Soda, "A Universal Modeling Method for Wooden Shear/Nonshear Walls,” Journal of Structural and Construction Engineering, Transactions of AIJ, No. 639, 2009, pp. 889-896. 